This version of the article "Knight, R. (2015) Empirical population and public health ethics: A review and critical analysis to advance robust empirical-normative inquiry. Health. DOI: $10.1177 / 1363459315583156$ ” is not the final version.

We acknowledge the publisher’s (SAGE Publications) copyright.

Here is a link to the final published version of the article:

http://hea.sagepub.com/content/early/2015/05/07/1363459315583156.abstract 


\title{
Empirical population and public health ethics: A review and critical analysis to advance robust empirical-normative inquiry
}

\begin{abstract}
The field of population and public health ethics (PPHE) has yet to fully embrace the generation of evidence as an important project. This article reviews the philosophical debates related to the 'empirical turn' in clinical bioethics, and critically analyses how population and public health ethics has and can engage with the philosophical implications of generating empirical data within the task of normative inquiry. A set of five conceptual and theoretical issues pertaining to population health that are unresolved and could potentially benefit from empirical PPHE approaches to normative inquiry are discussed. Each issue differs from traditional empirical bioethical approaches in that they emphasise: (1) concerns related to the population; (2) “upstream” policy-relevant health interventions - within and outside of the health care system; and (3) the prevention of illness and disease. Within each theoretical issue, a conceptual example from population and public health approaches to HIV prevention and health promotion are interrogated. Based on the review and critical analysis, this article concludes that empirical-normative approaches to population and public health ethics would be most usefully pursued as an iterative project (rather than as a linear project), in which the normative informs the empirical questions to be asked and new empirical evidence constantly directs conceptualizations of what constitutes morally robust public health practices. Finally, a conceptualization of an empirical population and public health ethics is advanced in order to open up new interdisciplinary 'spaces' in which empirical and normative approaches to ethical inquiry are transparently (and ethically) integrated.
\end{abstract}

Keywords: Population and public health; empirical ethics; HIV/AIDS; empirical methods 


\section{Introduction}

The field of bioethics has experienced several important changes during the past several decades. One such development has been both the inclusion and generation of empirical data within the bioethical task of normative inquiry. ${ }^{1}$ Frequently characterized as an ‘empirical turn’ (Frith, 2010; Ten Have \& Lelie, 1998) - and today referred to as empirical ethics - the philosophical and methodological implications of this transformation have been vigorously debated. A simultaneous discussion has taken place in the advancement of another area of normative inquiry that is anchored within public health: public health ethics. Although frequently contested in its origins (Petrini, 2010), Bayer and Fairchild (2004) suggest this field first emerged, in part, from a series of infectious disease outbreaks that exposed the insufficiency of some of the contemporary bioethical frameworks, specifically those that aimed to provide moral evaluations for various public health actions (e.g., quarantine practices during the SARS outbreaks of those who were asymptomatic in the absence of diagnostic tests). As public health ethics has continued to evolve, some theorists have also begun to take up many of the issues espoused by social scientists and demographers studying concepts, theories and data related to population health and the social and structural determinants of health, thereby leading some to refer to this emergent field as population and public health ethics. Population and public health ethics differs from traditional orientations of bioethics in that these approaches aim to: (1) emphasize moral evaluations related to the population, alongside those of the individual; (2) acknowledge that many “upstream” interventions and influences on health occur outside of the health care system; and (3) emphasise the prevention of illness and disease (Canadian Institutes of Health Research, 2012).

\footnotetext{
${ }^{1}$ Normative ethical theory refers to a part of philosophical ethics concerned, in large part, with general theoretical questions such as 'what makes various acts right or wrong?' or 'how should one act, morally speaking?'
}

? 
Notably, as population and public health ethics (PPHE) advanced and took up various approaches to engaging with empirical data within normative inquiry, it appears to have done so without engaging the methodological and philosophical discussions previously considered within the realm of empirical ethics. And, as the current review critically interrogates, for the most part, those engaging in PPHE have not considered the task of data generation as an important component of their work. As a result, it remains unclear how far the discussions within empirical ethics can inform or differentiate empirical approaches within PPHE. The timing is therefore ideal to begin a dialogue about how PPHE can (and should) consider the generation of empirical data as an important part of the task of normative inquiry.

\section{The evolution of empirical ethics: Mapping the terrain}

In the late 1980s and early 1990s, a variety of authors began to put forth pleas to bring empirical methods and theories into bioethical normative inquiry. The rationale behind these calls involved a range of issues related to dissatisfaction with the practical utility of bioethics from clinicians, as well as from some ethicists whose frameworks required additional context (e.g., those practicing feminist and casuistry ethics) (Borry, Schotsmans, \& Dierickx, 2004; Musschenga, 2005; Parker, 2009). For example, some argued that, within clinical practice, much of the ethical theory did not sufficiently align with the realities faced by patients and clinicians (Hoffmaster, 1992). As Baron (1989) described the 'taken-for-granted' and demarcated roles of ethicists and practitioners at the time: 'Bioethicists tend to leave the 'facts' of clinical medicine to the doctors; their task then is to apply elegant and compelling arguments from first principles of ethics... to these undisputed and indisputable facts' (p. 3).

Concurrently, sociological critiques argued that bioethics over-idealised rational thought while concomitantly excluding pertinent cultural issues that can influence clinical interactions (Frith, 2010; Hedgecoe, 2004; Musschenga, 2005; Parker, 2009). For example, scholars have argued that bioethics was overly deductive in argumentation, and that the prescriptive potential of the present-day bioethical 
frameworks was derived solely on 'rational' justifications of ethical theories abstracted from reality (Hedgecoe, 2004; Lopez, 2004). Similar to the dissatisfaction expressed by practitioners, these critiques argued that bioethics over-focussed on developing and justifying ethical theories, with little attention to the practical utility or contextual conditions within patients' and practitioners' everyday and actual experiences.

Despite the call for more evidence in bioethical inquiry, there has also been disciplinary resistance to the so-called empirical turn, with some arguing that analytical skills that require in-depth training and experience in philosophy, as well as sophisticated understandings of normative theory, is required (cf. Brassington 2013). Moreover, as philosophers and social scientists sought to bridge the disciplinary 'gaps' between their respective fields, a set of philosophical arguments against the socalled 'empirical turn’ arose, thereby challenging a variety of meta-ethical ${ }^{2}$ and epistemological concerns. First, some bioethicists feared that, in submitting to the 'empirical turn' in bioethics, ethics could no longer hold true to the philosophical method that, heretofore, required a degree of abstraction in the development of ethical theory. For example, Callahan (1996) argued that bioethics should be constructed to disregard social and cultural factors in order to avoid the 'dangerous' realm of moral relativism (e.g., in which each individual has their own ethical "truths" and a universal ethical theory need not apply). If, for example, normative theory emphasises experience and context (e.g., historical, social and cultural contexts) over the development of a universal normative theory, critics argued that bioethics will lose its prescriptive character, and therefore moral relativism is unavoidable (Van der Scheer \& Widdershoven, 2004).

${ }^{2}$ Broadly, meta-ethics is a branch of ethical philosophy that seeks to interrogate and better understand the 'nature' of ethical properties, arguments and evaluations, including those that take place within the realm of normative ethics. 
Second, some argued that bringing the empirical into normative inquiry would result in a purely descriptive endeavour because it is logically invalid to infer a conclusion based on a series of premises that are contingent on modality or are fact-based and value-ridden (Borry et al., 2004). For example, Hume’s Law (Hume \& Selby-Bigge, 1896) suggests that an "ought” statement cannot be derived from a set of “is” premises (the 'is-ought' fallacy). Moore’s (1903) Principia Ethica raises concerns about the naturalistic fallacy, suggesting that it is fallacious to qualify an action as moral or good based on natural properties. For example, concepts that can be empirically measured (at least to some extent), such as desirability or pleasantness, should not be considered proxies or equivalent to moral or good (concepts that are not generally considered empirically measurable within a scientific epistemology), though these concepts may both be ascribed to the same social acts. Others argued that the 'empirical turn' is a manifestation of medicine's emphasis on evidence-based medicine (Borry, Schotsmans, \& Dierickx, 2005) rather than a turn based on logical reasoning within normative inquiry (Culpepper \& Gilbert, 1999; Kerridge, Lowe, \& Henry, 1998). For example, some authors have argued that these issues raise a fact-value problem in which the generation and presentation of evidence is inherently normative and can only offer partial and biased glimpses into so-called 'facts' (though the importance of evidence within these discussions are not disavowed altogether) (Dunn \& Ives, 2009; Goldenberg, 2005). As a result, some argue that bringing empirical methods and theories into the normative risks the undue privileging of 'Grade 1' or 'gold standards' of evidence (Kerridge et al., 1998) and lead to clinical ‘decision trees’ that exclude opportunities for normative inquiry (Jacoby, 2006).

Nonetheless, many continued to argue in favour of advancing empirical-normative inquiry. For example, in defense of empirical ethics and in response to the is-ought fallacy, Reiter-Theil (2004) points out Hans Albert’s (2000) "Bridge-Principles" in which he argues the "is” and the "ought" must be separate, but that in order to have a duty to perform a given act (an "ought"), one must be empirically capable of doing so (an "is"). Moreover, others argued that, if transparently and carefully 
carried out, explicating assumptions related to the empirical and the normative can allay many of the concerns pertaining to the naturalistic fallacy and the fact-value distinction (De Vries \& Gordijn, 2009; Molewijk \& Widdershoven, 2012). For example, Molewijk and Widdershoven argue that all empirical approaches to ethics should be explicit about how they handle - from a meta-ethical perspective - the interactions between the empirical data, normative reasoning and the moral conclusion (e.g., acknowledging one's rationale and methods within their work), thereby attenuating many of the metaethical concerns.

\section{Typologies and methodologies of empirical ethics}

While a variety of definitions have been advanced, most share the understanding that empirical ethics actively integrates empirical research and normative analysis of data and evidence regarding a moral issue, followed by a normative conclusion (McMillan \& Hope, 2008; Molewijk \& Widdershoven, 2012). A variety of authors have proposed various typologies to describe and classify the different ways in which this takes place. For example, Borry et al. (2004) describe three different roles for empirical research in bioethical reflection and decision-making. First, empirical research can be used to describe the moral question by examining 'reality-revealing' questions (what, why, how, who, where and when) pertaining to an ethical issue, as well as to potentially reveal new issues that were not previously considered an 'ethical issue' (e.g., the times that meals are served to various patients). Secondly, empirical research is used to assess the moral question and object (e.g., assessing the degree of normativity attributed to the "factual”). And, thirdly, empirical approaches can be used to evaluate the normative decision-making process in order to delineate any unexpected or unintended consequences that arose and that will hold moral relevance for subsequent ethical deliberation.

Also in 2004, Molewijk, Stiggelbout, Otten, Dupuis, and Kievit described a set of typologies in order to reveal the extent to which theorists relate to empirical data as either positioning moral theory 
or a given social practice as constituting the 'final moral arbiter'. Molewijk et al. (2004) clarify their rationale for this classification system: 'if the morality of a social practice and moral theory are not in agreement with one another, which should be adapted: social practice, moral theory, both or neither?' (p. 56). When it is the moral theory that requires revisions, Molewijk et al. considers this an inductive (bottom-up) approach; when it is the social practices that require transformation, it is referred to as a deductive (top-down) approach. While a variety of inductive or deductive approaches were described, Molewijk et al argue in favour of what they termed integrated empirical ethics, in which normative and empirical are considered mutually constitutive (integrative) and interdependent; in this approach, ethicists and descriptive scientists work together to integrate moral theory and empirical data in order to reach a normative conclusion. More recently, in 2009, Kon (2009a) developed a target article for a special issue in the American Journal of Bioethics that sought to classify and define how empirical research informs normative ethics. After having this target paper critically reviewed by others in the field in the special issue, Kon noted that virtually no attention had been given to the is-ought fallacy and he declared that a conceivable dialogical consensus had been met: “it is settled: the 'is' can (and should) inform the 'ought'!” (2009b).

From a conceptual perspective, it is important to point out a distinction that some authors have made regarding whether or not empirical ethics 'counts' if it is simply drawing on existing evidence (e.g., scientific literature; data repositories) versus engaging in the generation of evidence through the use of various social scientific methods. Whereas some authors suggest that empirical evidence requires the generation of new, context-specific evidence (Molewijk \& Widdershoven, 2012), others suggest that the inclusion of evidence (whether generated within the task of normative inquiry or not) is just as likely to be subjected to the strengths and weaknesses ascribed to empirical ethics. For those engaging in data generation, many have suggested that qualitative methods - particularly, ethnographic methods - provide the 'thick description' needed to inform bioethical deliberations that is often absent 
within quantitative or statistical descriptions of a problem (Kon, 2009a; Kon, 2009b; Hoffmaster, 1992).

\section{Empirical approaches within population and public health ethics: A snapshot of the field}

It is worth reviewing the extent to which the generation of empirical data is considered or engaged within the task of normative inquiry within the expanding field of PPHE. For instance, there are a number of conceptual frameworks developed within PPHE approaches to normative inquiry - many of which seek to provide evidence-based decision-making tools for policy makers (Petrini, 2010). Among these, perhaps one of the most accepted frameworks (Walton \& Mengwasser, 2012) is the Nuffield Council on Bioethics Stewardship Model (Nuffield Council on Bioethics, 2007) - a framework that seeks to provide policy makers with a tool to assess evidence in order to determine the moral permissibility of a public health policy and/or action. While the framework encourages rigorous approaches to evaluating evidence, concerns related to data generation and normative-empirical inquiry remain absent. Similarly, among those researchers and theorists who 'brand' themselves as being engaged in PPHE, their work tends to invariably draw on already-existing evidence (with some important exceptions), rather than the active integration of empirical research and normative analysis regarding a specific moral issue. Powers and Faden’s (2006) influential book Social Justice, for example, eloquently argues that, in order to determine how complex social and economic environments influence health and well-being, normative theory and empirical data must be considered together, not in isolation. Nonetheless, further reading of their justification tacitly distils a set of demarcated roles between empirical researchers generating evidence and the ethicists engaging in normative inquiry about the evidence. It seems that for those working in PPHE, the task of generating and evaluating empirical data remains a linear, static process, generated by empirical researchers and passed to ethicists for moral evaluation. While an important and valuable endeavour, there remains a need to interrogate how empirical methods can (or ought to) be advanced within PPHE. 
It is also worth exploring how the work of those outside of PPHE (e.g., those who may not 'brand' themselves as working within PPHE) might relate to the ways in which we may begin to conceptualize an empirical PPHE. For example, the emerging field of impact ethics aims to engage in bioethical discussions and considers science as an important (but subservient) tool for promoting human good; and, many of the published works in this area have engaged in debates relevant to public health. However, they, too, do not appear to emphasize or integrate empirical methods within their work (cf. Impact Ethics, 2013). There may also be much to learn from other areas such as narrative ethics in which the individual or patient is explicitly acknowledged as also representing a 'true' ethicist. For example, narrative ethics acknowledges that most ethical acts and decisions are enacted by the patient, not the ethicist or clinician; indeed, this work recognises that the ethical decision-making practices of individuals have value and 'matter' (cf. Charon \& Montello, 2002).

Disciplines within the social sciences (e.g., sociology; anthropology) also have a strong tendency to both generate data related to population and public health, followed by a conclusion about what actions ought to be taken. Yet, there are also important differences with how one might conceptualize and advance empirical-normative inquiry within PPHE. Most importantly, learning lessons from the growing pains experienced by the wider field of empirical bioethics, the practical integration of empirical-normative processes in PPHE would shift away from traditional empirical and social scientific research approaches in which moral conclusions are considered largely 'rational' and 'scientific', rather than explicitly (and transparently) engaging and integrating evidence with normative theory. In doing so, for example, it becomes possible to avoid some of the aforementioned meta-ethical fallacies (e.g., fact-value distinctions) that tend to arise within scientific endeavours that seek to advance a degree of moral progress. 
While the vast majority of those working in (or parallel to) the field of PPHE have not incorporated data generation within their work, there is an exemplary study by Wolff and De-Shalit that merits discussion (2007). Wolff and De-Shalit conducted an empirical study theoretically grounded on a modified operational approach to Martha Nussbaum’s (2000) capabilities theory to identify groups that are among the least advantaged members of society. By turning to social science methods, the authors explore whether public policies that seek to ameliorate one form of disadvantage will inadvertently create another form of disadvantage or, instead, produce an overall good. While Wolff (2009) describes the aim of this research as 'not to engage in normative consequences or analysis of the social determinants of health', they do indicate that their use of empirical methods is to provide more realistic context in their political philosophy, thereby offering a potential 'glimpse' into how one might begin to conceive of an empirical PPHE.

\section{Operationalizing an empirical PPHE}

In order to advance direction for where empirical PPHE efforts should be addressed, a broad operational definition that positions empirical PPHE as actively engaging in the generation of data is the most helpful at this point - particularly when considering that many working in PPHE have already at least considered or 'used' evidence within their normative inquiry. Specifically, the following definition regarding empirical PPHE is proposed: the active integration of individual- (e.g., experiential) and population-level (e.g., data pertaining to the health-wealth gradient) empirical research and normative analysis of the generated data regarding a moral issue, followed by a normative conclusion. This research agenda requires interdisciplinary approaches and collaborations, with ethicists and empirical researchers working side by side, including models in which ethicists engage in and with empirical research, as well as models in which empirical researchers engage with normative theory. Indeed, this research agenda suggests a dynamic process in the generation, and constant re-evaluation, of ethical imperatives in population and public health: the normative informs 
the empirical questions to be asked; the answers to those questions demand critical reflection on the validity of the ethical norms and values; and so on.

\section{What sorts of data can be generated in empirical PPHE?}

In order to further explore the extent to which the generation of evidence can contribute to empirical PPHE, a set of modified typologies put forth by De Vries and Gordijn (2009) and influenced by others are offered (Birnbacher, 1999; Molewijk et al., 2004; Sulmasy \& Sugarman, 2001). The choice of typologies and divisions are for heuristic and analytic purposes and are not meant to be exhaustive. Within each typology, a set of illustrative examples of traditional approaches to empirical bioethics as described by De Vries and Gordijn (2009) are provided. Next, a set of conceptual and theoretical issues pertaining to population health that are unresolved and could potentially benefit from empirical PPHE approaches to normative inquiry are offered. Finally, within each typology, an example from public health approaches to HIV prevention and health promotion is provided. As will be highlighted, HIV represents an ideal issue to begin an exploration into issues pertaining to empirical PPHE approaches, given that there are a variety of issues that arise within and outside of the clinic, provide opportunities for prevention and concern both individual- and population-level outcomes and interests.

(1) Description and analysis of the actual conduct of a group with respect to a morally relevant issue

As De Vries and Gordijn (2009) point out, Sulmasy \& Sugarman (2001) describe two ways in which the actual conduct of a group may hold relevance within normative inquiry: (a) to explore the extent to which social practices align with an ethical theory; and (b) to evaluate the extent to which policies and/or procedures are aligning with a given set of moral norms that are required within a particular clinical setting. To illustrate this typology, De Vries and Gordijn (2009) offer the example of a study by van Thiel and van Delden (1997) that explores the extent to which nurses working in a nursing home 
are acting in accordance with ethical norms pertaining to patient autonomy. The findings of the study reveal that, given many patients in this setting lacked full independence and rational decision-making capacities, the nurses were unable to meet the demands of the criteria required by the principle of autonomy. As a result, the authors suggest that these finding reveal the need to either revise the ethical criteria around autonomy or implement new procedures to ensure nurses can meet the demands of patient autonomy.

A PPHE approach could expand upon individual-level interactions to focus on how public health policy (e.g., within and beyond the health care system) responds to various population subgroups with respect to a PPHE moral issue (e.g., health equity; social justice). For example, an empirical analysis of the variegated supply and demand of a specific resource (e.g., an intervention) among population sub-groups could determine whether efforts are meeting a theoretically equitable distribution of resources. This sort of study could be informed by designing and creating populationbased studies (e.g., cohort and cross-sectional studies), as well as a variety of ethnographic techniques to provide illustrative examples of how individuals are experiencing their interactions with a resource or social practice that holds relevance to a moral issue (e.g., equity or social justice). Such an empirical PPHE could also be used to test the (potential or actual) effectiveness of policy or policy approaches. For example, consider a government policy that was developed with the premise that individuals ought to take primary responsibility for a given health behaviour (e.g., alcohol consumption) because individuals know how best to regulate their behaviour. A PPHE approach could question this presumption, and if it shows that the government's reasons are poor, it also raises questions about the sustainability of the policy. Ultimately, the transparent normative analysis of these data can inform a moral conclusion related to whether or not adequate measures have been taken to (re)distribute a resource (and if these actions ought to be revised or not), or whether the ethical theory should be revised. 
From within the realm of HIV, consider how various social and structural factors have been identified as determinants of HIV infection. Given these considerations, an exploration into how various ‘natural experiments’ (e.g., “upstream” interventions such as housing and employment programs) are being distributed among various vulnerable and disadvantaged populations could distil the extent to which public resources are being distributed according to an ethical theory (e.g., equity; social justice). Such a study could generate and analyse aggregate and individual-level data to determine how resources are distributed, as well as how individuals are experiencing the intervention. For example, are there unintended consequences that may arise? How are individual benefits negotiated with those of the broader population? Thus, the empirical data could provide context to engage in an ethical deliberation in order to provide a normative conclusion as to whether the intervention is justifiable and/or if efforts ought to be addressed elsewhere.

(2) Description and analysis of the actual moral opinions and reasoning patterns of those involved in a certain practice

Empirical study into the moral opinions of individuals involved in a specific practice has largely been advanced in terms of exploring the acceptability of implementing policies pertaining to an ethical theory (Birnbacher, 1999; De Vries and Gordijn, 2009). There is also another type of empirical research that considers a group’s moral opinions as a genuine source of ethical theory development. De Vries and Gordijn (2009) describes another study by van Delden and van Thiel (1998) that finds nurses working in a nursing home conceptualized issues related to patient autonomy as being context- and case-specific (and therefore difficult to relate to a top-down, universal ethical theory). Given these findings, they argue for a multidimensional emphasis on the principle of respect for autonomy within that clinical setting. 
In terms of moral opinions and PPHE issues, empirical PPHE could benefit our understanding of how various individuals will perceive and thus potentially experience a population health intervention. For example, given that populations can be considerably heterogeneous (e.g., in terms of culture, moral preferences and beliefs), it is not unreasonable to assume that some individuals and groups will not share the values related to the ethical theory supporting a population intervention (e.g., social communitarian approaches to welfare are not likely to be supported by libertarians). This raises an important issue for PPHE in considering what actions to take when an intervention is 'morally' opposed by some members of the population. As Musschenga (2005) argues, these sorts of moral acceptability issues can speak to the implementation feasibility and fidelity of an intervention. Thus, empirical-normative research could explore the extent to which various groups’ moral opinions regarding an intervention will render the intervention either unfeasible, or, alternatively, whether there may be various actions that can be taken to attenuate or mitigate various negative experiences associated with specific moral concerns. Indeed, this sort of reasoning treads dangerously close to committing a series of meta-ethical fallacies previously discussed. Thus, in advancing empiricalnormative approaches such as those discussed by Molewijk et al (2004), careful and transparent empirical-normative deliberative techniques would be required to determine the extent to which a groups' moral concerns ought to contribute to the revising of either the social practice (the intervention), the ethical theory, both or neither.

With respect to HIV, empirical PPHE could clarify how various individuals and populations view (e.g., morally) the shift from voluntary approaches to HIV testing (in which an individual must voluntarily seek an HIV test) to routine or opt-out testing approaches (in which individuals are routinely offered an HIV test when they interact with the health care system). For example, consider how the experience of being offered an HIV test might differ for an individual who is morally opposed to such a practice. This sort of data could offer insights into various strategies that could be 
implemented to ameliorate these experiences - both within and beyond the clinic (e.g., among public health's on-going efforts to de-stigmatize HIV; clinical practices related to routinely offering testing services). Normative-empirical inquiry in this area could yield insights into the resolution of these sorts of issues by determining the morally justifiable actions in a world with various morally- and socially ascribed meanings attached to issues such as HIV and HIV testing practices.

\section{(3) Making ethics more context-sensitive}

As Birnbacher (1999) argues, issues related to the effectiveness of a proposed norm is contextdependent and requires empirical data. De Vries and Gordijn (2009) offer the example of a study (Musschenga, 2005) in which receiving informed consent within some settings is a particular challenge and may not be feasible to the degree that the ethical theory requires. As a result, the authors suggest revising the ethical theory and the procedures to attain informed consent.

Given the complexity of considering various intersecting influences on health within a PPHE approach (e.g., micro-, meso- and macro-level influences), an empirical study could seek to identify the breadth of the moral arguments that are raised about a population health issue in order to identify knowledge gaps that require additional evidence. In this sense, the empirical work is a systematic exploration of the ethical debates in order to provide a clear, 'thick' description of the 'ethical landscape' and the various discussions that are and have transpired. Thus, this approach has the capacity to methodically identify normative claims that have been put forth based on premises that are unsubstantiated by evidence. The normative component of this work can engage critically with the ethical theories that have been advanced, while reaching a normative conclusion may first require the additional generation of data (e.g., where the various 'gaps' were identified). For example, this sort of an analysis may serve primarily to identify 'gaps', rather than a means to come to a normative conclusion. 
Within the substantive example of HIV, it is helpful to explore the issue of stigma and various approaches to HIV testing. For example, Knight et al. (2014) found that, within a review of the literature pertaining to ethical discussions of stigma and HIV testing, two moral issues emerged pertaining to the adoption of routine testing approaches: (1) HIV-related stigma will be exacerbated because more people will become aware that they have HIV and therefore exposed to HIV-related stigma; and (2) HIV-related stigma will become normalized through routine approaches to HIV testing and therefore HIV-related stigma will be reduced. As the authors argue, these divergent claims are based largely on assumptions, rather than on empirically substantiated premises. However, as the authors suggest, these claims can be subjected to empirical investigation. Thus, these findings reveal how the capacity to develop a robust normative conclusion will benefit from the generation of empirical work pertaining to various HIV testing approaches and HIV-related stigma.

\section{(4) Descriptions of facts relevant to normative arguments}

As revealed in the previous typology, normative claims based on logical reasoning are frequently based on assumptions or premises that can be empirically examined in order to delineate the extent to which the claim is 'true' or 'false' (Sulmasy \& Sugarman, 2001). To illustrate this type of empirical ethics, De Vries and Gordijn (2009) offers the example of substituted judgement in which a family member is required to make the decisions for a loved one who has lost their decision-making capacities. In describing a study conducted by Shalowitz, Garrett-Mayer and Wendler (2006), the findings reveal the extent to which 'surrogates' are not very effective in making the decisions that the patient originally wanted. As a result, these empirical findings bring into question the moral permissibility of the substituted judgement standard thought to be morally required based on the assumption that substitutes would be able to determine the patient's wishes. 
Within the realm of empirical PPHE, the scope of inquiry could be expanded to explore the emerging set of critiques indicating how various features of population health interventions serve to disproportionately benefit advantaged groups, thereby exacerbating health inequity (Benach, Malmusi, Yasui, \& Martinez, 2013; Lorenc, Petticrew, Welch, \& Tugwell, 2012). For example, there is emerging concern that various features of targeted public health interventions may exacerbate health inequity (McLaren, McIntyre, \& Kirkpatrick, 2010), raising moral concerns regarding their use (Bayer, 2008). Criticisms of this approach include the potential for 'victim blaming', stigmatization and an overemphasis on individual-level lifestyle factors (e.g., 'risky' behaviour). An empirical PPHE could yield benefits in this area by generating and analysing data in order to determine the extent to which these moral concerns are warranted, and to draw a normative conclusion as to whether or not the targeted interventions are morally justifiable. Indeed, these are difficult questions that cannot be answered through empirical or normative exploration alone, but require an integrated approach.

HIV represents an important case study with respect to an analysis of targeted public health interventions and discourses, as a variety of socially- and behaviourally-based targeted approaches have been implemented during the past 30+ years. For a recent example, consider the role of antiretroviral ‘treatment as prevention’ (TasP). Despite the evidence showing the promise of TasP in reducing HIV incidence (Montaner et al., 2010), a variety of ethical concerns have been articulated related to the potential for this intervention to burden HIV positive individuals (as they are being recommended ART, regardless of their individual-level CD4 count) and may, yet again, disregard social contexts (Nguyen, Bajos, Dubois-Arber, O’Malley, \& Pirkle, 2011). Thus, concerns related to an individual's autonomy and the potential for targeted and coercive seeking and testing strategies during implementation have emerged within this debate (Vonn, 2012). Empirical work in this area could seek to characterize the extent to which a 'burden' negatively impacts individuals and population sub-groups 'targeted' for treatment, as well to determine the potential population-level benefits that can be accrued 
in this approach (e.g., reductions in HIV incidence). In order to draw a normative conclusion, empirical-normative analyses would seek to transparently arrive at a theoretical 'balance' of the various findings and interests (i.e., based on an ethical theory).

(5) Showing the normative aspects of science, technologies or organizations

De Vries and Gordijn (2009) explain that some empirical-ethical studies seek to reveal the normative aspects that arise within scientific theories and technologies. A study by Molewijk (2006) is described in which the development and use of a new decision-support tool to assist patient decision-making is implemented and investigated. Molewijk found that the introduction of the 'evidence-based' decision support tool changed the process of decision-making (for both the surgeon and the patient) by making it more difficult to decide on a final treatment choice, thereby raising a set of moral questions as to how the tool should be implemented within clinical practice.

In an empirical PPHE, a critical interrogation of empirical data and the claims and recommendations that authors and researchers advance is required. In responding to the fact-value critiques that arose in empirical ethics, considerations must be given to the implicit normative dimensions of evidence. For example, within the scientific literature, recommendations for action are frequently unsubstantiated by scientific methods based on a scientific-rationalist epistemological paradigm (in which evidence is theoretically value free and objective). As a result, PPHE researchers generating their own data need to implement systematic and transparent methods related to the evaluation of data within normative inquiry. For example, using the 'Questions for Writing a Metamethodology Section in Empirical Ethics Papers' by Molewijk et al. (2004) will provide a starting point to reflexively engage with one’s own biases (e.g., values or beliefs) on the production of data and how the normative conclusions were drawn based on the interactions with empirical evidence. 
Within the realm of HIV, consider empirical epidemiological population-based studies that find that male circumcision in high prevalence settings can reduce heterosexual male acquisition of HIV. As a result, the three - now famous - randomized trials in Sub-Saharan Africa unanimously recommended a full scale-up of male circumcision within high prevalence settings ( $c f$. Auvert, Taljaard, Lagarde, Sobngwi-Tambekou, Sitta, \& Puren, 2005; Bailey et al., 2007; Gray et al., 2007). Nonetheless, the validity of these recommendations has been contested and debated for a variety of reasons. For example, de Camargo Jr, de Oliveira Mendonça, Perrey, and Giami (2013) describe in their analysis of the debate (among those in favour and those against scale up), given the lack of engagement in interdisciplinary analysis of the data (e.g., from normative perspectives) and the potential outcomes of 'real world' effectiveness, "there is... no way of asserting... which of the two sides is being driven by facts and which is allowing itself to get carried away by values” (p.12). An empirical PPHE would seek to explicitly bridge the missing empirical-normative deliberation in order to open up new spaces for ethical discussion. For example, ethno-epidemiologic methods - an approach that integrates data derived from both ethnographic methods and epidemiologic research - could offer insights into both the efficacy and effectiveness of such an intervention within various implementation contexts, as well as reveal empirical insights on how male circumcision is perceived and experienced by individuals (and their partners, families and communities) in order to draw normative conclusions on the moral permissibility of this practice.

\section{Advancing empirical population and public health ethics}

There is value in explicitly examining and questioning whether and how evidence and normative analysis should be bridged in seeking a moral conclusion in order to acknowledge and attend to the various meta-ethical questions previously raised. For example, while it remains unclear whether or not the various meta-ethical questions require resolution (Molewijk \& Widdershoven, 2012), there is value in explicating how the philosophical methods and normative theory employed consider or position 
issues such as moral relativism, abstraction and the various meta-ethical fallacies that empiricism is often charged with when entering the normative domain. Empirical PPHE requires engagement in practical philosophy; if it is to be action-guiding and claim ethical validity, we need a measure for such moral authority. Thus, this field should advance a set of careful and concerted reflexive practices to critically interrogate empirical data, as well as our various normative assumptions and biases (e.g., by drawing on various theoretical orientations from the sociology of bioethics (cf. de Vries, 2004)).

This importance is underlined when it is noted that various global actors are advocating for the generation of PPHE-relevant data, making the timing ideal to engage in meaningful discussions about how PPHE can and should generate data within normative inquiry. For example, within the Canadian context, the Canadian Institutes of Health Research's Institute of Population and Public Health ${ }^{5}$ identifies the development of methods and theory within the realm of PPHE as a part of their strategic mandate, and the use of empirical evidence is leveraged as one potential pathway through which to achieve this aim. There will be much to learn by engaging in interdisciplinary approaches, including working with those from fields that have already been engaging in similar (but conceptually, philosophically and methodologically different) empirical-normative endeavours. Indeed, in advancing theoretical and conceptual orientations pertaining to an empirical PPHE, the intention is not to create a new or 'siloed' discipline or field, but rather to open up new interdisciplinary spaces and opportunities for those of us in this field to work together in order to advance a degree of rigour in normative and empirical inquiry in population and public health research.

The generation of evidence in PPHE will have a distinct set of implications for various potential biases, generalizability issues, as well as the normative assessments of population-based evidence. As illustrated in the conceptual and substantive examples, the "kinds" of evidence evaluated within PPHE are distinct from empirical bioethics in that it requires additional considerations of population-level 
empirical methods and theoretical frameworks. Thus, there is value added in generating these issues from within the rapidly developing sphere of population health intervention research (PHIR). Within PHIR, for example, population-level interventions are defined as those that have the capacity to 'shift the distribution of health risk by addressing the underlying social, economic and environmental conditions’ (Hawe \& Potvin, 2009). In studying population-level interventions, researchers can employ methods that are experimental, quasi-experimental, observational and both qualitative and/or quantitative. Indeed, this leaves those engaging in PPHE with questions pertaining to how previously established "gold standards" of evidence should be applied within a normative-empirical analysis. For example, within this approach, studies that use non-experimental designs (e.g., natural experiments) may be likely to yield more meaningful evidence for an empirical PPHE than a randomized controlled trial (e.g., in which researchers frequently attempt to 'control for context'). Finally, the complexity of interpreting population-based results re-emphasizes the need for interdisciplinarity and critical approaches in empirical PPHE. As Dawson (2012) articulates, scientific challenges and nuances that flow from empirical population-based studies should not be underestimated and require careful and ongoing scientific and ethical consideration.

The conflation of 'facts' and 'values' in empirical work can be problematic; however, explicating how the normative conclusions and recommendations are derived from a normative analysis of empirical data can serve to provide transparent (and ethical) guidance as to how and/or why a conclusion is derived. In doing 'ethical' empirical-normative inquiry, the source origins of both the methodological and philosophical frameworks should be addressed to the fullest extent possible (Hurst, 2010), along with clear, transparent rationale with respect to how the empirical and normative interacted to arrive at a moral conclusion (Molewijk \& Frith, 2009). To achieve this will require that those conducting empirical work move beyond exclusive considerations of research ethics to 
integrating an on-going consideration of how their findings can be bridged with a (inherently normative) recommendation for action.

\section{Conclusion}

Advancing empirical PPHE approaches will be most helpful by actively engaging in the generation of

new data. These empirical-normative approaches to PPHE should not be conceptualized or practiced as linear, but rather as a constant feedback loop in which the normative informs the empirical questions to be asked and new evidence constantly directs the recommendations for morally robust public health practices. These critical approaches to empirical PPHE can provide opportunities to develop more philosophical and empirical rigour within this field. It may be, after all, a very difficult task to 'do the right thing' in our efforts to improve population health without engaging in a set of robust, transparent and ethical empirical and normative practices.

\section{References}

Albert, H. (2000). Kritischer Rationalismus Vier Kapitel zur Kritik illusionaeren Denkens. Tuebingen: UTB Mohr Siebeck.

Auvert, B., Taljaard, D., Lagarde, E., Sobngwi-Tambekou, J., Sitta, R., \& Puren, A. (2005). Randomized, controlled intervention trial of male circumcision for reduction of HIV infection risk: The ANRS 1265 Trial. PLOS Medicine, 2, 1112-1122.

Bailey, R. C., Moses, S., Parker, C. B., Agot, K., Maclean, I., Krieger, J. N., ... \& Ndinya-Achola, J. O. (2007). Male circumcision for HIV prevention in young men in Kisumu, Kenya: a randomised controlled trial. The Lancet, 369(9562), 643-656.

Baron, R.J. (1989). Dogmatics, empirics, and moral medicine. Hastings Center Report, 19(1), 41-42.

Bayer, R. (2008). Stigma and the ethics of public health: Not can we but should we. Social Science \& Medicine, 67(3), 463-472. 
Bayer, R. \& Fairchild, A.L. (2004). The Genesis of Public Health Ethics. Bioethics, 18(6), 473-492.

Benach, J., Malmusi, D., Yasui, Y., \& Martinez, J.M. (2013). A new typology of policies to tackle health inequalities and scenarios of impact based on Rose's population approach. Journal of Epidemiology \& Community Health, 67(3), 286-291.

Birnbacher, D. (1999). Ethics and social science: Which kind of co-operation? Ethical Theory and Moral Practice, 2(4), 319-336.

Borry, P., Schotsmans, P., \& Dierickx, K. (2004). What is the role of empirical research in bioethical reflection and decision-making? An ethical analysis. Medicine, Health Care and Philosophy, 7(1), 41-53.

Borry, P., Schotsmans, P., Dierickx, K. (2005). The birth of the empirical turn in bioethics. Bioethics, 19(1), 49-71.

Brassington, I. (2013). What's the Point of Philosophical Bioethics? Health Care Analysis, 21(1), 2030.

Callahan, D. (1996). Ethics without abstraction: squaring the circle. Journal of Medical Ethics, 22(2), 69-71.

Canadian Institutes of Health Research (2012). Population Health Ethics. Retrieved on 15 July 2014 from: http://www.cihr-irsc.gc.ca/e/41867.html.

Charon, R. \& Montello, M. (2002). Stories Matter: The role of narrative in medical ethics. Routledge: London.

Culpepper, L., \& Gilbert, T.T. (1999). Evidence and ethics. The Lancet, 353(9155), 829-831.

Dawson, L. (2012). The Devil in the Details: Thorough Assessment of Evidence and Ethics Is Needed in Evaluating New HIV Prevention Methods. The American Journal of Bioethics, 12(6), 33-34. de Camargo Jr, K. R., de Oliveira Mendonça, A. L., Perrey, C., \& Giami, A. (2013). Male circumcision and HIV: A controversy study on facts and values. Global public health, 8(7), 769-783. 
De Vries, R. (2004). How can we help? From ‘sociology in’ to ‘sociology of' bioethics. Journal of Law, Medicine and Ethics, 32(2), 279-292.

De Vries, R., \& Gordijn, B. (2009). Empirical Ethics and Its Alleged Meta-Ethical Fallacies. Bioethics, 23(4), 193-201.

Dunn, M., \& Ives, J. (2009). Methodology, Epistemology, and Empirical Bioethics Research: A Constructivist Commentary. The American Journal of Bioethics, 9, 93-95.

Frith, L. (2010). Symbiotic empirical ethics: A practical methodology. Bioethics, 26(4), 198-206.

Goldenberg, M.J. (2005). Evidence-based ethics? On evidence-based practice and the "empirical turn” from normative bioethics. BMC Medical Ethics, 6(1), 11-19.

Gray, R. H., Kigozi, G., Serwadda, D., Makumbi, F., Watya, S., Nalugoda, F., ... \& Wawer, M. J. (2007). Male circumcision for HIV prevention in men in Rakai, Uganda: a randomised trial. The Lancet, 369(9562), 657-666.

Hawe, P. \& Potvin, L. (2009). What is population health intervention research? Canadian Journal of Public Health, 100(1), I8-I14.

Hedgecoe, A.M. (2004). Critical Bioethics: Beyond the Social Science Critique of Applied Ethics. Bioethics, 18(2), 120-143.

Hoffmaster, B. (1992). Can ethnography save the life of medical ethics? Social Science \& Medicine, 35(12), 1421-1431.

Hume, D. \& Selby-Bigge, L.A. (Eds.) (1896). A Treatise of Human Nature. Oxford: Oxford University Press.

Hurst, S. (2010). What “empirical turn in bioethics?” Bioethics, 24(8), 439-444.

Impact Ethics. (2013). About Impact Ethics: Making a difference in bioethics. Retreived from http://www.impactethics.ca/about/. 
Jacoby, L.H. (2006). For bioethics - The role of empirical research. The American Journal of Bioethics, 6(3), 58-59.

Jennings, B. (2003). Frameworks for ethics in public health. Acta Bioethica, 9(2),165-176.

Kerridge, I., Lowe, M., \& Henry, D. (1998). Personal paper: Ethics and evidence based medicine. BMJ: British Medical Journal, 316(7138), 1151-1153.

Knight, R., Shoveller, J., Greyson, D., Kerr, T., Gilbert, M., \& Shannon, K. (2014). Advancing population and public health ethics regarding HIV testing: a scoping review. Critical Public Health, 24(3), 283-295.

Kon, A.A. (2009a). The role of empirical research in bioethics. The American Journal of Bioethics, 9, 59-65.

Kon, A.A. (2009b). It is settled: The ‘is' can (and should) inform the 'ought'!. The American Journal of Bioethics, 9, W4-W6.

Lopez, J. (2004). How sociology can save bioethics... maybe. Sociology of Health \& Illness, 26(7), 875-896.

Lorenc, T., Petticrew, M., Welch, V., \& Tugwell, P. (2012). What types of interventions generate inequalities? Evidence from systematic reviews. Journal of Epidemiology \& Community Health, 67(2), 190-193.

McLaren, L., McIntyre, L., \& Kirkpatrick, S. (2010). Rose's population strategy of prevention need not increase social inequalities in health. International Journal of Epidemiology, 39(2), 372-377.

McMillan, J. \& Hope, T. (2008). The possibility of empirical psychiatric ethics. In G. Widdershoven, J. McMillan, T. Hope, \& L. van der Scheer (Eds.), Empirical Ethics in Psychiatry (pp. 9-22). Oxford: Oxford University Press. 
Molewijk, B. (2006). Risky business: Individualised evidence-based decision support and the ideal of patient autonomy: An integrated empirical ethics study (Unpublished doctoral dissertation). Leiden University, Leiden.

Molewijk, B. \& Frith, L. (2009). Empirical ethics: Who is the Don Quixote? Bioethics, 23(4), ii-iv. Molewijk, B., Stiggelbout, A.M., Otten, W., Dupuis, H.M., Kievit, J. (2004). Scientific contribution. Empirical data and moral theory. A plea for integrated empirical ethics. Medicine, Health Care and Philosophy, 7(1), 55-69.

Molewijk, B. \& Widdershoven, G.A.M. (2012). Don’t solve the issues! Cambridge Quarterly of Healthcare Ethics, 21(04), 448-456.

Montaner, J.S.G., Lima, V.D., Barrios, R., Yip, B., Wood, E., Kerr, T., et al. (2010). Association of highly active antiretroviral therapy coverage, population viral load, and yearly new HIV diagnoses in British Columbia, Canada: a population-based study. The Lancet, 376(9740), 532539.

Moore, G.E. (1903). Principia Ethica. Cambridge: Cambridge University Press.

Musschenga, A. (2005). Empirical ethics, context-sensitivity, and contextualism. The Journal of Medicine and Philosophy, 30(5), 467-490.

Nguyen, V.K., Bajos, N., Dubois-Arber, F., O’Malley, J., \& Pirkle, C.M. (2011). Remedicalizing an epidemic: From HIV treatment as prevention to HIV treatment is prevention. AIDS, 25(3), 291293.

Nuffield Council on Bioethics. (2007). Public Health: Ethical Issues. London: Nuffield Council on Bioethics.

Nussbaum, M. (2000). Women and Human Development. Cambridge: Cambridge University Press. Parker, M. (2009). Two concepts of empirical ethics. Bioethics, 23(4), 202-213. 
Petrini, C. (2010). Theoretical models and operational frameworks in public health ethics. International Journal of Environmental Research and Public Health, 7(1), 189-202.

Powers, M. \& Faden, R. (2006). Social justice: The moral foundations of public health and health policy. New York: Oxford University Press.

Reiter-Theil, S. (2004). Does empirical research make bioethics more relevant? "The embedded researcher” as a methodological approach. Medicine, Health Care and Philosophy, 7(1), 17-29.

Shalowitz, D., Garrett-Mayer, E., \& Wendler, D. (2006). The Accuracy of Surrogate Decision Makers. A Systematic Review. Archives of Internal Medicine,166, 493-497.

Sulmasy, D.P. \& Sugarman, J. (2001). The Many Methods of Medical Ethics (Or, Thirteen Ways of Looking at a Blackbird). In D. P. Sulmasy \& J. Sugarman (Eds.), Methods of Medical Ethics (pp. 3-18). Georgetown: Georgetown University Press.

Ten Have, H.A., \& Lelie, A. (1998). Medical ethics research between theory and practice. Theoretical Medicine and Bioethics, 19(3), 263-276.

van Delden, J.J.M. \& van Thiel, G.J.M.W. (1998). Reflective Equilibrium as a Normative-Empirical Model in Bioethics. In W. van der Burg \& T. van Willigenburg (Eds.), Reflective Equilibrium (pp. 251-259). Dordrecht: Kluwer Academic Publishers.

van der Scheer, L., \& Widdershoven, G. (2004). Integrated empirical ethics: Loss of normativity? Medicine, Health Care and Philosophy, 7(1), 71-79.

van Thiel, G.J.M.W. \& van Delden, J.J.M. (1997). Dealing with patient autonomy in Dutch nursing homes. Health Care in Later Life, 2, 177-186.

Vonn, M. (2012). “British Columbia’s ‘seek and treat’ strategy: A cautionary tale on privacy rights and informed consent for HIV testing.” HIV/AIDS Policy \& Law Review, 16, 15-18.

Walton, M., \& Mengwasser, E. (2012). An Ethical Evaluation of Evidence: A Stewardship Approach To Public Health Policy. Public Health Ethics, 5(1), 16-21. 
Wolff, J. (2009). Disadvantage, Risk and the Social Determinants of Health. Public Health Ethics, 2(3), 214-223.

Wolff , J. \& De-Shalit, A. (2007). Disadvantage. Oxford: Oxford University Press. 